\title{
New Challenges in the Meteorology of the Upper Atmosphere*
}

\author{
By W. W. KeLlOGG**
}

It is a great pleasure and honor for me to speak to you tonight. Scientists have known for years that one cannot study something as large as the earth without joining with other people in other countries. Meteorologists have been particularly aware of this, since the atmosphere certainly knows no national boundaries, and it speaks its own universal language as it moves across the face of the earth. So, ladies and gentlemen, I come to you, with Dr. Fujita, to speak about a subject that concerns us equally in all parts of the world. I only wish that we all could speak in the language of the wind so that Mr. Takeda would not be required to translate my words to you.

My subject is the upper atmosphere, but I will limit it that part of the atmosphere that is above the level that can be reached by the meteorologist's balloons, but not as high as the upper ionosphere, where the atmosphere is so very rare that it no longer behaves like the atmosphere as we meteorologists know it. By that I mean that above about $150 \mathrm{~km}$ the air is highly ionized, and it is no longer free to move about under pressure forces, but is locked in the grip of the earth's magnetic field. Therefore, meteorologists can no longer use their usual techniques to study it, and tend to leave it to the physicists to study.

So the part of the atmosphere, that I will talk about is that lying above our usual balloon observation network, above about $30 \mathrm{~km}$, and below 100 or $150 \mathrm{~km}$. You will no doubt be wondering why we are interested in this region. You may well ask: Does it have any affect on the weather? Is it of interest scientifically? Is it any different from the lower atmosphere? The answer to all these questions is "Yes", and there are three main reasons for our increased interest. In the short time I have tonight I will only have time to tell you these three reasons and give you a very brief sketch of what this part of the atmosphere is like, and how it behaves. Perhaps what I tell you will interest you enough so that you will want to learn more about it.

One important reason for meteorologists new look at the upper atmosphere is their ability to study it with small rockets.

There are rockets that are small and simple enough to be fairly cheap, and yet

* Public Lecture given at the 11th Pacific Science Congress, Tokyo, August 23, 1966.

** National Center of Atmospheric Researches, U.S.A. 
capable of carrying a payload of from 2 to 5 kilograms to an altitude of 70 to $80 \mathrm{~km}$. Some of them just eject radar chaff - like this small rocket - and the chaff can be followed by a radar on the ground, and this gives wind speed and direction as it slowly falls.

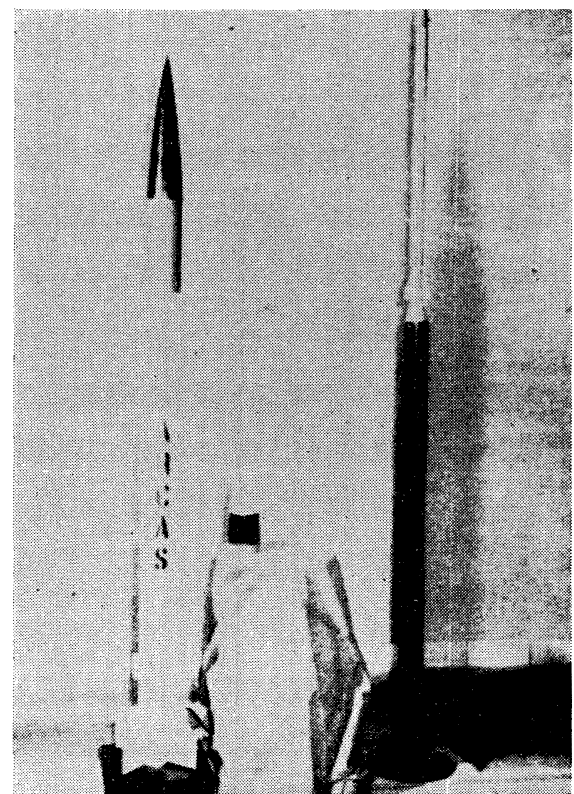

《Slide $1 》$

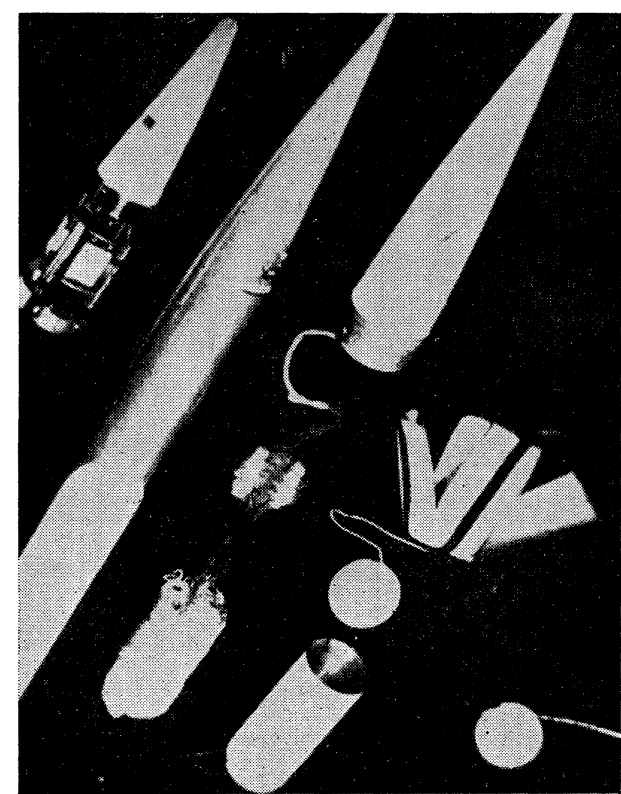

《Slide $2 》$

This somewhat larger rocket, called an Arcas, has a package that comes down on a parachute, and it gives us wind from the drift of the parachute as it falls, and also temperature, measured by a tiny bead that changes its electrical conductivity with temperature.

This is a schematic picture showing how it works. You will see the falling parachute with its radio transmitter, and the ground station tracking it. The ground station is a standard kind used to follow balloons. The Japanese meteorological rocket uses a similar system.

In the United States we shoot about one thousand of the meteorological rockets per year, and the cost of these rockets is about the same as for the ten thousand balloons that we use per year. Although this is not as many as we would like to have, it has given us a rather good picture of how the stratosphere behaves.

And now other countries are firing such rockets, including Japan, from stations all over the world, and we have the beginning of a real network similar to the balloon radiosonde network that already exists. In Japan Kagoshima is the main launching 


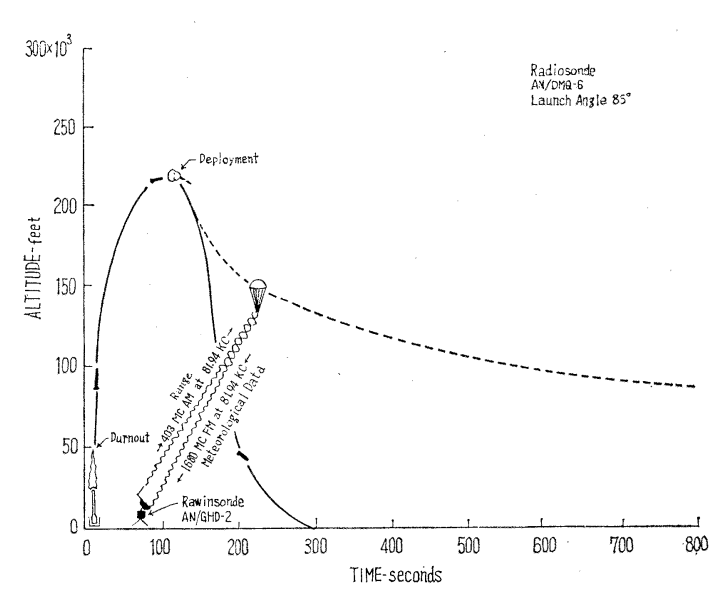

《Slide 3 》

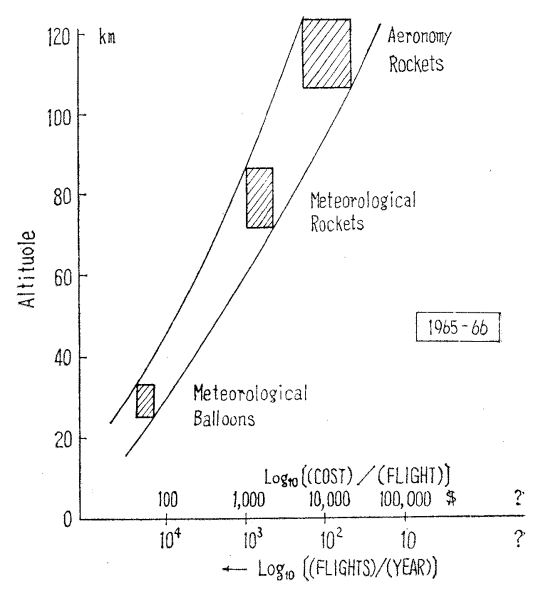

《Slide 4 》

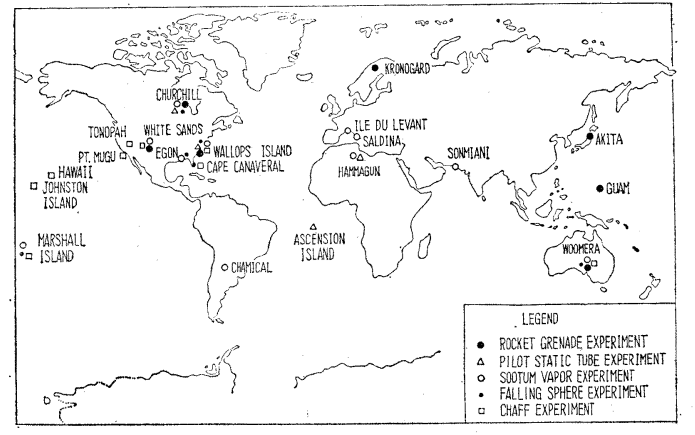

《Slide 5 》 Map of mesosphere soundings conducted during and since IGY.

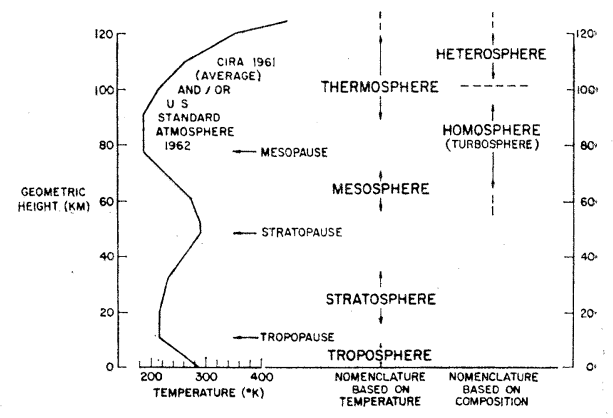

《Slide 6 》 The temperature distribution and nomenclature of the upper atmosphere.

now, but it is hoped that another meteorological rocket site can be located in northern Japan.

Now, what have we learned from these observations? We have learned a great deal, and I will just tell you about a few of these discoveries. But first let me remind you about the names we give the parts of the atmosphere. Even in my country, where we speak the same language (more or less), we sometimes have trouble with the names. The "stratosphere" is the region with a generally increasing temperature with increasing height. Above that is the "mesosphere", with a decreasing temperature with height. Finally, the "thermosphere" with a temperature that increases to $1000^{\circ}$ to $1500^{\circ} \mathrm{K}$, merges with what we may call "space". Our astronauts fly in the thermosphere, and they are hardly aware that there is any atmosphere at all at $200 \mathrm{~km}$ where they orbit around the earth. 


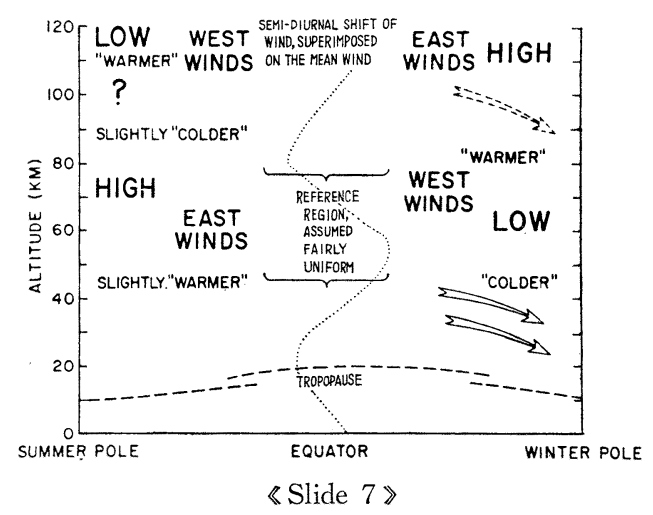

This is a diagram of how we find the upper atmosphere to move. You will see that it has a curious pattern of east winds and west winds. In the summer hemisphere, on the left side of the diagram, there are east winds in most of the stratosphere. These are very steady winds, and are caused by the air over the poles being warmed by sunlight, and this causes a great high pressure area over the poles. The air over the winter poles in the stratosphere, on the other hand, is cold, since little sunlight reaches it. This causes a cold low pressure area to form in the winder over the poles, and the west winds blow around this low pressure area.

If we draw a weather map at $30 \mathrm{~km}$, or at a pressure of $10 \mathrm{mb}$, which is at the

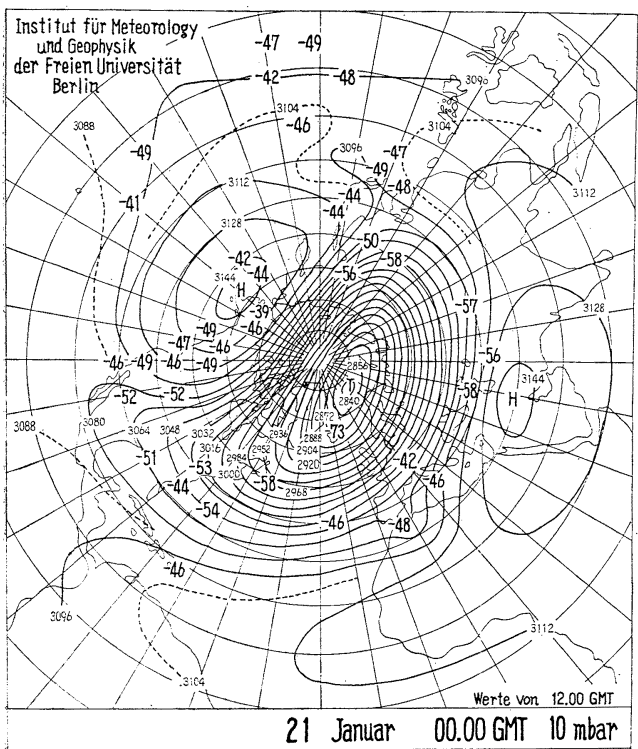

《Slide 8 Pressure patterns at the beginning of an "explosive warming".

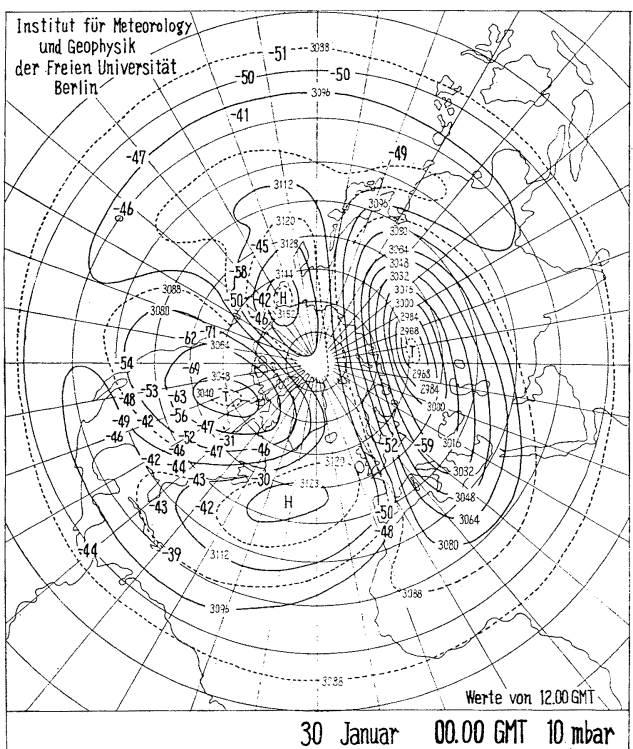

《Slide 9 》 Pressure patterns during the period of an "explosive warming". 
highest level we can reach with our balloons, we see the low pressure area over the cold winter pole. (These maps were drawn by meteorologists at the Free University of Berlin.) You cannot reach what is on this map, but you can see the contours of the $10 \mathrm{mb}$ pressure surface, and you can see how they cause the wind to blow counter-clockwise around the pole. This was for the year 1958, and is typical of the wintertime circulation most of the time. However, every year something very strange happens to this rather regular pattern, and it suddenly changes. When it changes the low pressure area splits in two.

This is the way it appeared in 1958, after it had split, and we have seen this happed nearly every year. At the same time as the splitting of the low pressure center occurs there is a very rapid "warming" of the stratospheric air on the side of each new low pressure center. For this reason we usually call this phenomenon a "stratospheric warming". The explanation for such sudden changes is still far from clear to us. However, I would like to mention two things that seem to be clear: First, our meteorological rockets tell us that the change seems to occur first at very high levels, above 40 or $50 \mathrm{~km}$. Second, on many occasions we have been able to relate these dramatic changes in the stratosphere with important changes in the weather patterns in the lower atmosphere. For example, several of the most severe outbreaks of cold polar air over the U.S. and Europe have followed a day or two after such stratospheric warmings. We are not yet sure of the relationship, but there is good reason to believe that we may be able to forcast such outbreaks of cold air, bringing freezing temperatures far southward, if we can observe these stratospheric warmings when they first begin in the middle of winter.

Now I will give you just a glimpse of how the atmosphere behaves still higher up,

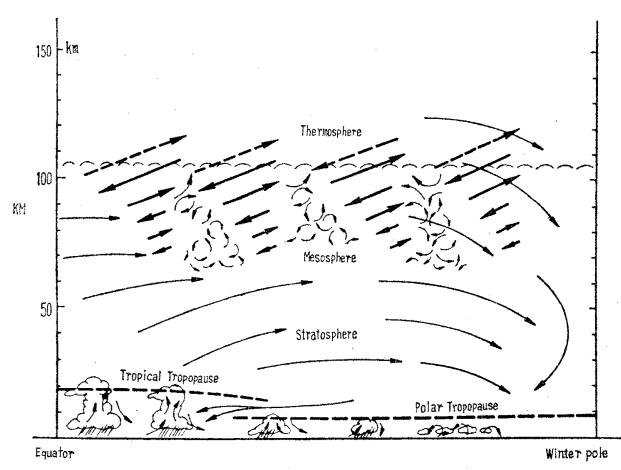

《Slide $10 》$ Schematic representation of the mixing processes in the atmosphere.

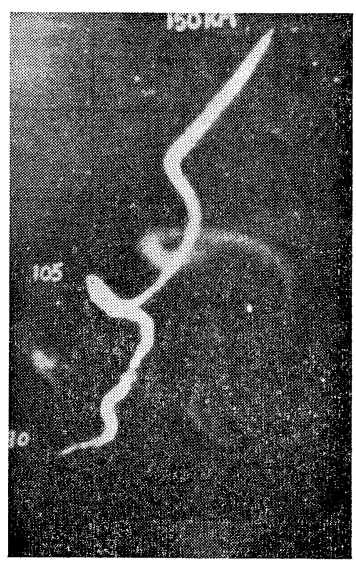

《Slide $11 》$ 
in the mesosphere and lower thermosphere. (You will remember that we defined these regions earlier.). This diagram shows heavy slanting arrows in this part of the atmosphere, and they represent a very intense kind of gravity wave. These gravity waves are like waves in a bowl of jelly that you shake sideways at the bottom. They are very violent at times, and so are the semi-diurnal tides that pull the upper atmosphere back and forth. These winds are much more violent and rapidly changing than any winds that we see in the lower atmosphere.

I only have time to show one picture of a sodium vapor trail made at twilight in which these rapidly varying winds can be seen. This is a double exposure, with the bright trail taken when the rocket was at the top of the picture, and the fairly trail was taken about a minute later. I just want you to see how very rapidly the wind has torn this straight line of smoke apart. Remember that one can heat a bucket of water by stirring it long enough. It takes a great deal of mechanical work to raise a fluid by a few degrees, but it can certainly be done. Wa have studied these winds, and the great amount of turbulency they produce, by means of such vapor trails. This kind of experiment has been done at many parts of the world now. And the conclusion that some people have come to is that the winds produced by gravity waves and tides can indeed heat the upper atmosphere in winter.

If we could now have Slide 7 again, I will show in a general way why this may be of importance. You will recall that in winter the stratosphere is cold over the poles, and there are west winds. You can also see that at higher levels there are east winds in winter, at about $100 \mathrm{~km}$, and this must mean that the air over the winter poles in the mesosphere is warmer than over the equator. Since there is no sunlight to warm this polar air, the source of heat must be sought elsewhere. Perhaps it is just this conversion of mechanical motion into heat, and we have good reason to think that this may be important.

There is another curious source of heat in winter over the poles, and this is the recombination of atomic oxygen as it is sucked downward from higher levels. Such a source of heating seems very likely, and it is something that is unique in the atmosphere. Nowhere else do we have a direct conversion of chemical energy, in the form of atomic oxygen, to heat.

This has been a very brief picture of the upper atmosphere, as seen by meteorologists. I wish I had time to tell you some of the other exciting things that we are learing about it. I have told you about the general patterns of the winds in the stratosphere, and how they change abruptly in winter. I have told you about the wave motions in the mesosphere that derive their energy from the lower atmosphere, and the mysterious source of heat in the polar atmosphere in winter. 
These are but a few of the features that we have found. Our main conclusion is this: That the atmosphere behaves as one complete system, and we must learn to understand how the upper part behaves before we can hope to understand the whole.

May I close by saying how very much I have enjoyed the opportunity to speak to this audience, and I hope that I will have the privilege of visiting Tokyo and its great university many times in the future.

(注：もとのスライドが不鮮明のため, Slide 3, 4, 5, 8, 9 の全体と, Slide 7, 10 の一部を 書き改めた。——編集委員) 